\section{How proteins find their DNA target}

Researchers have captured images of individual proteins searching for their DNAbinding sites, and have quantified parts of this process.

Zhe Liu and his team at the Howard Hughes Medical Institute in Ashburn, Virginia, looked at transcription factors — proteins that bind to specific genes to regulate their activity — in individual, living mouse embryonic stem cells. The researchers used microscopes to track single molecules of Sox 2 and Oct 4 , key stem-cell gene regulators. They found that the two molecules use trial and error to seek out their binding sites, by colliding with DNA, diffusing away and colliding again roughly 90 times before finding their targets. The process takes about 6 minutes and the factors remain bound to the target sites for about 12 to 14 seconds.

Sox 2 collides and then slides along short stretches of DNA. Sox 2 also binds before Oct4, helping it to find its home. Cell 156, 1274-1285 (2014)

\section{GLACIOLOGY}

\section{More of Greenland is starting to melt}

Once-stable glaciers in northeast Greenland are now shrinking as a result of regional warming.

Shfaqat Khan at the Technical University of Denmark in Kongens Lyngby and his colleagues analysed satellite and airborne-elevation measurements of three glaciers that comprise the 600-kilometre-long northeast Greenland ice stream. The measurements revealed that, after more than a quarter of a century of stability, this stream began to thin between 2003 and 2006. The team then looked at ocean and atmospheric temperature data and determined that warmer air temperatures, beginning in 2003, probably led to the melting of sea ice in the region, allowing the glaciers to flow more freely into the ocean.

These ice-loss measurements exceed projections made for this region, and so models of global sea-level rise may underestimate Greenland's contribution over the coming century.

Nature Clim. Change http://doi. org/rxb (2014)

\section{AGRICULTURE}

\section{Warming climate threatens crops}

Climate change could result in decreasing yields of staple food crops in most parts of the world from the 2030s onwards.

Andrew Challinor at the University of Leeds, UK, and his team compared the results of more than 1,700 simulations of climate change impacts - with and without various adaptation strategies - on annual wheat, rice and maize (corn) yields. The data suggest that, without adaptation, average food-crop supplies will decline by around 5\% per degree Celsius of warming.

Losses of wheat in temperate climates and rice in tropical environments can be avoided, or even reversed, by changing factors such as crop varieties, planting time, fertilizer use and irrigation. But such adaptation measures may provide little or no benefit for maize yields, particularly in tropical regions, the authors warn.

Nature Clim. Change http://doi. org/rw9 (2014)

\section{HUMAN EVOLUTION}

\section{Hominin explorers were poor planners}

Hominin migrations, such as those out of Africa, might have been led by indivduals with low levels of foresight.

A team led by Colin Wren at McGill University in Montreal, Canada, modelled the migratory behaviour of individuals, based on the complexity of their environments and their cognitive ability to assess and

COMMUNITY CHOICE

The most viewed papers in science

\title{
3D printing goes nanoscale
}

\section{(2) HIGHLY READ \\ on pubs.acs.org in February}

Researchers have used a threedimensional (3D) printing technique to stack nanometre-scale polymer threads on top of one another, forming a tiny wall.

A promising 3D nanoscale printing method involves spinning nanofibres out of a liquid under a strong electrical field. But only certain shapes have been printed this way, because the fibres tend to electrically repel each other. To solve this problem, Minhee Lee and Ho-Young Kim of Seoul National University fired polymer nanofibres onto a metal template sitting on top of a grounding plate that quickly drains the deposited fibres of charge. The fibres then spontaneously attract each other, and stack to form a freestanding wall.

The technique cannot yet be used to print objects with sharp corners but could still be useful for building, for example, tiny transistors, the authors say.

Langmuir 30, 1210-1214 (2014)

seek out better environments.

The model predicted that those with poorer foresight were more likely to stumble on a better habitat, and therefore disperse into new areas. Furthermore, homogeneous environments fostered exploration because the more constant level of resources allowed explorers to travel further than those in a more heterogeneous setting. J. Hum. Evol. http://doi.org/rwd (2014)

\section{PHYSICS}

\section{Micro-pump with no moving parts}

A pump can propel liquids along millimetre-sized channels at high speeds with no mechanical parts.

The pump, designed by Khashayar Khoshmanesh at the Royal Melbourne Institute of Technology University in Australia and his colleagues, is a droplet of metal - an alloy of gallium, indium and tin - that is held loosely in a spherical chamber in the middle of a Plexiglas channel. A slow chemical reaction in the metal droplet results in

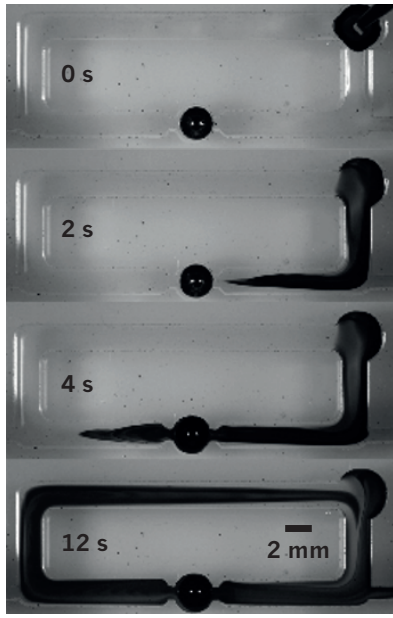

gallate anions diffusing to the droplet's surface. When a lowpower electric field is applied, the rearrangement of charges at the droplet's surface causes it to shift in its constrained space in such a way that the surrounding solution flows past it (pictured).

The pump might be useful in microscopic machines, the researchers say.

Proc. Natl Acad. Sci. USA 111, 3304-3309 (2014)

\section{$\rightarrow$ NATURE.COM}

For the latest research published by Naturevisit:

www.nature.com/latestresearch 